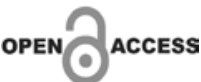

Correspondence addresses:

Dr. Alex Guedes

alexguedes2003@yahoo.com.br

Received: September 30, 2021

Revised: October 28, 2021

Accepted: November 21, 2021

Published: December 28, 2021

Data Availability Statement: All relevant data are within the paper and its Supporting Information files.

Funding: This work was the result of authors' initiative. There was no support of research or publication funds.

Competing interests: The authors have declared that no competing interests exist.

Copyright

(C) 2021 by Santa Casa

de Misericórdia da Bahia.

All rights reserved.

ISSN: 2526-5563

e-ISSN: 2764-2089

DOI: 10.35753
RESUMO DE ARTIGO

\section{Atualização na Avaliação por Imagens dos Sarcomas Ósseos e das Partes Moles}

\section{Update in Imaging Evaluation of Bone and Soft Tissue Sarcomas}

Alex Guedes $^{1 *}$, Marcelo Bragança dos Reis Oliveira² ${ }^{2}$ Adelina Sanches de Melo ${ }^{3}$, Clarissa Canella Moraes do Carmo ${ }^{4}$

${ }^{1}$ Grupo de Oncologia Ortopédica do Hospital Santa Izabel; Salvador, Bahia; ${ }^{2}$ Serviço de Traumatologia Ortopédica do Hospital Clementino Fraga Filho, Universidade Federal do Rio de Janeiro; Rio de Janeiro, Rio de Janeiro; ${ }^{3}$ Serviço de Medicina Nuclear do Hospital Santa Izabel; Salvador, Bahia; ${ }^{4}$ Departamento de Radiologia, Universidade Federal Fluminense; Niterói, Rio de Janeiro, Brasil

The evolution in imaging evaluation of musculoskeletal sarcomas contributed to a significant improvement in the prognosis and survival of patients with these neoplasms. The precise characterization of these lesions, using the most appropriate imaging modalities to each clinical condition presented, is of paramount importance in the design of the therapeutic approach to be instituted, with a direct impact on clinical outcomes. The present paper synopsis seeks to update the reader regarding imaging methodologies in the context of local and systemic evaluation of bone sarcomas and soft tissues.

Keywords: Diagnostic Imaging; Multimodal Image; Neoplasms, Connective Tissue; Neoplasms, Bone Tissue; Sarcoma.

A evolução na avaliação por imagens dos sarcomas musculoesqueléticos contribuiu para uma melhora significativa no prognóstico e na sobrevida dos portadores destas neoplasias. A caracterização precisa destas lesões, mediante utilização das modalidades de imagem mais adequadas a cada condição clínica apresentada, é de suma importância no delineamento da abordagem terapêutica a ser instituída, com impacto direto sobre os desfechos clínicos. A presente sinopse de artigo busca atualizar o leitor a propósito das metodologias de imagem no contexto da avaliação local e sistêmica dos sarcomas ósseos e das partes moles.

Palavras-chave: Diagnóstico por Imagem; Imagem Multimodal; Neoplasias de Tecido Conjuntivo; Neoplasias de Tecido Ósseo; Sarcoma.

\section{Introdução}

Na avaliação dos sarcomas musculoesqueléticos, a acurácia diagnóstica depende da correlação entre clínica, bioimagem e patologia - a revisão multidisciplinar desses aspectos definirá o planejamento adequado do tratamento instituído. ${ }^{1,2}$

Resumo de Artigo: Guedes A, Oliveira MBR, Melo AS, Carmo CCM. Update in Imaging Evaluation of Bone and Soft Tissue Sarcomas. [Published online: 2021-11-11] Rev Bras Ortop. Available from: https://www.thieme-connect.de/products/ejournals/ pdf/10.1055/s-0041-1736569.pdf?articleLanguage=en. DOI:10.1055/s-0041-1736569. 
Após a avaliação clínica inicial, radiografias são solicitadas para confirmar a presença de neoplasia ou para fornecer outra explicação ao paciente sobre os sintomas. ${ }^{1}$

Na suspeita de um sarcoma musculoesquelético, outras métodos de imagem são necessários para caracterizar as lesões, informando sobre tamanho, margens, realce, homogeneidade versus heterogeneidade da matriz, para estabelecer seu comportamento biológico.

Esta avaliação anátomo-morfológica foi recentemente aprimorada, incluindo caracterização metabólica e funcional,,${ }^{1,3}$ ampliando a capacidade de detecção dessas neoplasias, permitindo sua avaliação no contexto do acompanhamento da doença e da resposta terapêutica. ${ }^{4}$

Por outro lado, estudos recentes ${ }^{5,6}$ identificaram uma alta porcentagem de solicitações de testes de imagem inapropriadas para a avaliação de neoplasoas musculoesqueléticas, o que justifica a necessidade de disseminação de maior conhecimento sobre o tema.

O objetivo deste resumo é atualizar o leitor sobre os métodos de imagem utilizados no contexto da avaliação local e sistêmica de sarcomas ósseos e sarcomas de tecidos moles.

\section{Avaliação de Imagem de Sarcomas Musculo- esqueléticos}

A avaliação por imagem é fundamental na abordagem dos srcomas musculoesqueléticos. ${ }^{1}$ Vale mencionar que esta avaliação deve preceder uma biópsia ${ }^{6}$ porque: (a) permite um planejamento preciso da coleta na região do acesso cirúrgico definitivo e na área mais representativa da lesão; (b) facilita o diagnóstico diferencial, permitindo uma correlação histopatológica; (c) evita prévia manipulação que pode afetar as imagens, gerando edemas e artefatos, especialmente na imagem por ressonância magnética (IRM). ${ }^{7}$

\section{Avaliação da Localização (Tabela 1)}

Exame Radiológico
O exame radiológico do segmento afetado, em pelo menos dois segmentos ortogonais, estabelece a base da avaliação por imagem. ${ }^{1,2,4} \mathrm{~A}$ não obtenção de radiografias está associada a um significativo atraso no diagnóstico do sarcoma ósseo. ${ }^{8}$

Geralmente, os sarcomas ósseos são caracterizados por rápido crescimento, apresenta uma ampla área de transição com o osso afetado, limites imprecisos, aspecto permeativo, destruição cortical e/ou reação periosteal interrompida, em raios solares, lamelar ou amorfo. ${ }^{1,9}$

$\mathrm{Na}$ ausência de evidências confiáveis, o exame radiográfico é um método razoável na avaliação inicial de tumores de partes moles, permitindo detectar e definir o padrão de mineralização, auxiliar no diagnóstico específico e diferencial e informar sobre densidade e envolvimento ósseo. . $^{1,2,4,9}$

Este método apresenta baixa sensibilidade na avaliação de lesões esteolíticas, detectáveis apenas após a perda de massa óssea entre 30 e $50 \%{ }^{10}$ Diante da alta suspeita, a investigação deve ser continuada, mesmo quando a aparência é normal.

\section{$\underline{\text { Ultrassom }}$}

A ultrassonografia é um método para a avaliação inicial de tumores superficiais de partes moles, ${ }^{9}$ identificados pela impedância acústica e distorção da anatomia local.

Os sarcomas de partes moles são geralmente hipoecoicos e hipervasculares e o aparecimento de tumores sólidos geralmente é inespecífico. Há consenso quanto à indicação na avaliação de tumores pequenos $(<5 \mathrm{~cm})$ e superficiais, distinguindo lipomas, malformações vasculares, estruturas císticas e tumores sólidos. ${ }^{9}$ Lesões maiores e profundas não permitem avaliação adequada por essa modalidade. ${ }^{9}$

\section{Tomografia Computadorizada (TC)}

TC A TC tem melhor resolução espacial que a ressonância magnética (RM), detectando 
Tabela 1. Métodos de imagens usados na avaliação da localização de sarcomas musculoesqueléticos.

\begin{tabular}{|c|c|c|}
\hline Método & Vantagens & Disvantagens \\
\hline $\begin{array}{l}\text { Radiografias } \\
\text { convencionais }\end{array}$ & $\begin{array}{l}\text { - Acessível; } \\
\text { - Base de avaliação de imagem - triagem para outras } \\
\text { metodologias; } \\
\text { - Fornece toda a imagem anatômica da região de interesse; } \\
\text { - Resolução espacial superior do osso trabecular; } \\
\text { - Sarcomas ósseos: tamanho, forma e comportamento } \\
\text { biológico; } \\
\text { - Sarcomas de tecidos moles: mineralização, densidade e } \\
\text { envolvimento ósseo; } \\
\text { - Diagnóstico definitivo em } 80 \% \text { dos tumores ósseos. }\end{array}$ & $\begin{array}{l}\text { - Avaliação limitada para tumores de } \\
\text { tecidos moles, } \\
\text { - especialmente para tumores pequenos } \\
\text { e superficiais; } \\
\text { - Resolução de contraste baixa; } \\
\text { - Baixa sensibilidade em lesões } \\
\text { osteolíticas; } \\
\text { - Radiação ionizante variável. }\end{array}$ \\
\hline $\begin{array}{l}\text { Tomografia } \\
\text { computadorizada }\end{array}$ & $\begin{array}{l}\text { - Acessível; } \\
\text { - Avaliação multiplanar - imagens de áreas anatômicas } \\
\text { extensas; } \\
\text { - Detecta diferenças muito pequenas na densidade das } \\
\text { junções; } \\
\text { - Fácil aquisição, tempo de esaneamento rápido, tempo de } \\
\text { resultado maior do que a IRM; } \\
\text { - Resolução espacial, definição de mineralização da matriz e } \\
\text { envolvimento cortical superior à ressonância magnética; } \\
\text { - Papel bem estabelecido como guia para biópsias ósseas; } \\
\text { - Planejamento de amputações - customização de próteses; } \\
\text { - Simulação e planejamento de tratamentos de radioterapia. }\end{array}$ & $\begin{array}{l}\text { - Resolução de contraste mais baixa } \\
\text { em comparação com a ressonância } \\
\text { magnética; } \\
\text { - Pequenas lesões podem não ser } \\
\text { incorporadas aos cortes; } \\
\text { - Radiação ionizante variável; } \\
\text { - Reações alérgicas ao contraste } \\
\text { iodado, que podem ser leves } \\
\text { (incomuns) ou graves (raras); } \\
\text { - Uso contraindicado de contraste em } \\
\text { pacientes alérgicos ao iodo. }\end{array}$ \\
\hline $\begin{array}{l}\text { Ressonância } \\
\text { magnética }\end{array}$ & $\begin{array}{l}\text { - Menos acessível; } \\
\text { - Imagem multiplanar direta; } \\
\text { - Sem radiação ionizante; } \\
\text { - Maior resolução de contraste de tecidos moles, maior do } \\
\text { que na TC; } \\
\text { - Mais sensível na determinação da extensão dos sarcomas } \\
\text { musculoesqueléticos. }\end{array}$ & $\begin{array}{l}\text { - Custo mais elevado; } \\
\text { - Espaço pequeno para a realização do } \\
\text { exame (claustrofobia, dificuldades } \\
\text { nos exames de pacientes obesos); } \\
\text { - Contra-indicações de ressonância } \\
\text { magnética relacionadas ao campo } \\
\text { magnético gerado; } \\
\text { - O tempo para aquisição da imagem } \\
\text { pode exigir sedação; } \\
\text { - Reações alérgicas ao gadolínio (muito } \\
\text { raras). }\end{array}$ \\
\hline Ultrassom & $\begin{array}{l}\text { - Acessível; } \\
\text { - Imagem em tempo real; } \\
\text { - Sem radiação ionizante; } \\
\text { - Diferencia tumores sólidos de tumores císticos e } \\
\text { determina sua vascularização (Doppler); } \\
\text { - Melhor na avaliação de tumores de tecidos moles } \\
\text { pequenos e superficiais; } \\
\text { - Orienta biópsias de tecidos moles, prevenindo lesões } \\
\text { neurovasculares e evitando partes necróticas de tumores; } \\
\text { - Uso em condições em que a RM e/ou TC são } \\
\text { contraindicadas. }\end{array}$ & $\begin{array}{l}\text { - Método dependente do examinador; } \\
\text { - O aparecimento de tumores sólidos } \\
\text { geralmente é inespecífico; } \\
\text { - Menor resolução e contraste para TC } \\
\text { e RM; } \\
\text { - Tumores ósseos não podem ser } \\
\text { avaliados; } \\
\text { - Tumores de tecidos moles maiores } \\
\text { e mais profundos não permitem } \\
\text { avaliação adequada por este método. }\end{array}$ \\
\hline
\end{tabular}

diferenças muito pequenas na densidade tecidual. Apresenta maior sensibilidade do que as radiografias, identificando lesões que acometem $<40 \%$ do estoque ósseo. É superior na avaliação do esqueleto axial, das cinturas e dos ossos curtos da mão ou do pé.
Além disso, esse método permite orientar biópsias ósseas e também é indicado no planejamento de amputações, conduzindo a customização de próteses, sendo essencial na simulação e planejamento radioterápico. 
O aumento da disponibilidade da RM e a preocupação com a radiação limitaram o uso da TC na prática clínica. Os avanços tecnológicos resultaram em um "retorno" pela diminuição da exposição, por meio de diretrizes claras e limites de dose para uso clínico. Atualmente, os exames são realizados com frequência e duram poucos segundos, sendo, entretanto, pouco mais irradiantes que as radiografias.

\section{Imagem por Ressonância Magnética (IRM)}

IRM é mais sensível em determinar a extensão dos sarcomas musculoesqueléticos. Imagens multiplanares de alta resolução permitem caracterização adicional. ${ }^{1-4}$

Avalia melhor os elementos contidos nos sarcomas, ${ }^{1}$ discriminando entre água, gordura e sangue, revelando informações fisiológicas sobre um processo dinâmico da mesma forma que a cintilografia óssea. Deve incluir o segmento inteiro afetado, ${ }^{1,2}$ buscando identificar metástases salteadas.

A RM permite inferir características que auxiliam no diagnóstico diferencial de tumores de partes moles. As lesões malignas frequentemente apresentam realce, apresentando áreas de necrose e hemorragia que determinam um padrão heterogêneo. Pseudocápsula hipointensa ou edema peritumoral hiperintenso em imagens de recuperação ponderadas em T2 ou imagens de recuperação de inversão de curta duração (STIR) são frequentemente observados em sarcomas de tecidos moles. ${ }^{1}$

A técnica avançada de RM (Figuras 1 e 2), quando contextualizada pela história, exame físico e radiografias, são ferramentas importantes no diagnóstico e acompanhamento de pacientes com neoplasias musculoesqueléticas, evitando biópsias desnecessárias, aumentando a acurácia diagnóstica e eficácia do tratamento, além de melhorar o prognóstico e a sobrevida. ${ }^{4,7} \mathrm{O}$ estudo dinâmico de contraste (DCS) e sequências de difusão (DWI) e suscetibilidade magnética (SWI) são exemplos dessas técnicas.
As desvantagens da RM incluem espaço restrito, acometendo pacientes obesos e claustrofóbicos, tempo elevado para exames de imagem, além de contraindicações relacionadas ao campo magnético gerado.

\section{Avaliação Sistêmica (Tabela 2)}

Rais-X (Tórax) e TC (Tórax, Abdômen e Pelve)

Diretrizes indicam que, na ausência de evidências confiáveis, não é necessário realizar radiografia de tórax para estadiamento de uma suspeita de sarcoma musculo esquelético. Nessa condição, utiliza-se a TC de alta resolução, mais sensível na detecção de metástases. ${ }^{1,2,8}$

A National Comprehensive Cancer Network recomenda TC de abdome e pelve na avaliação de sarcomas de tecidos moles propensos à disseminação para esses locais. ${ }^{1,2}$

\section{$\underline{\text { Cintilografia Óssea }}$}

A cintilografia óssea é sensível, barata, disponível, com baixa exposição à radiação, isento de contraindicações e efeitos colaterais, e permite a avaliação de todo o esqueleto no mesmo tempo de imagem. Utiliza marcadores radioativos com meia-vida curta e alta afinidade pela atividade osteoblástica, refletindo mais eventos fisiológicos do que anatômicos.

O radiofármaco mais utilizado é o metilenodifosfonato marcado com tecnécio99m (MDP99mTc), que se liga à matriz óssea inorgânica onde há atividade proliferativa.

A cintilografia óssea é utilizada no estadiamento dos sarcomas ósseos, identificando lesões semelhantes ou metástases ósseas, pois a maioria induz à proliferação da matriz óssea, possibilitando sua captação. ${ }^{8}$ Possui menor acurácia no estadiamento de sarcomas de tecido mole, captados apenas nos estágios iniciais (fluxo e equilíbrio).

É útil no seguimento de neoplasias com alta taxa de recorrência ou potencial metastático e 
Figura 1. Técnica avançada de RM.

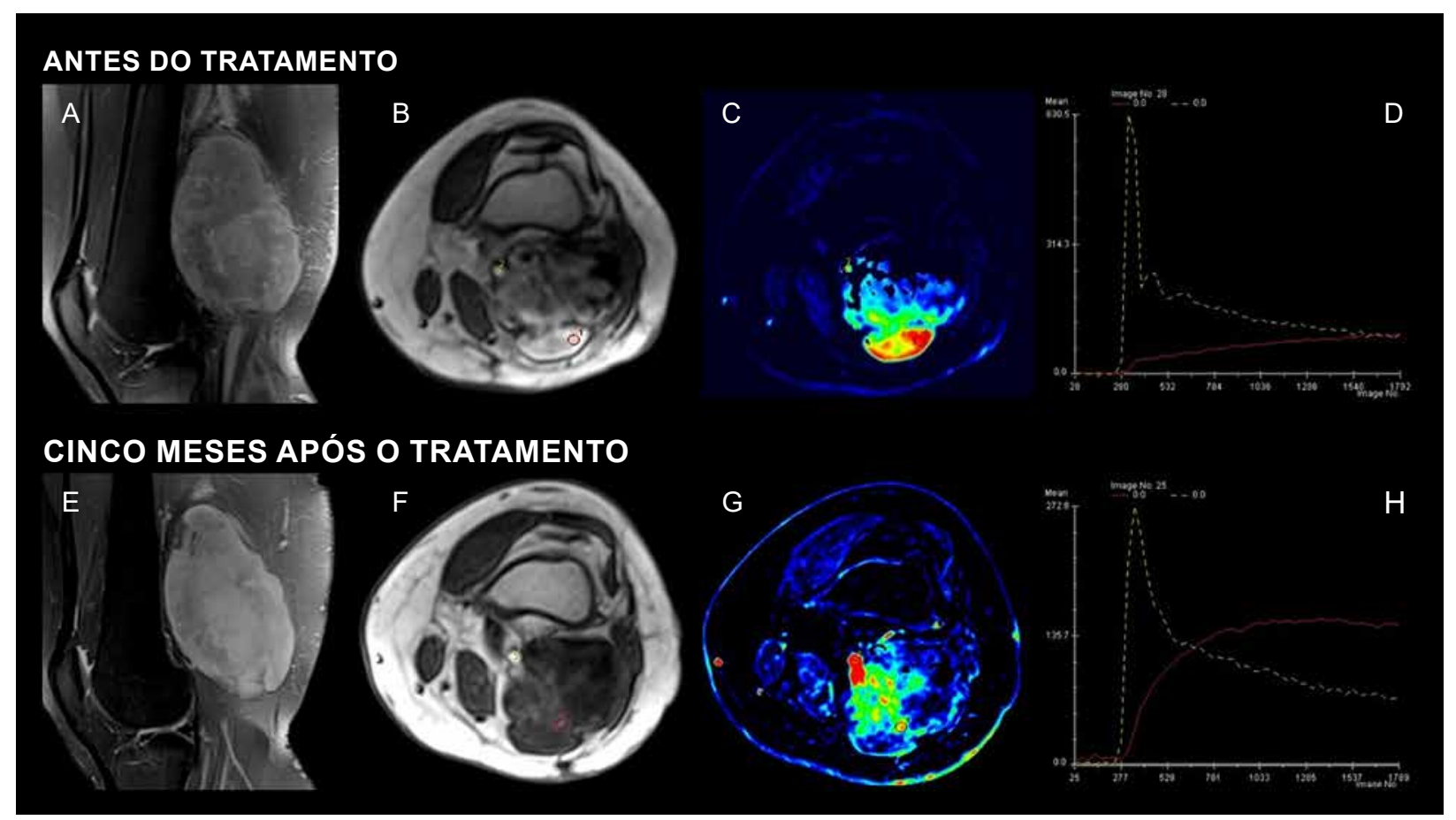

Homem, 29 anos, sarcoma de alto grau no joelho direito. Densidade protética sequencial com supressão de gordura no plano sagital antes do tratamento (A) demonstrando lesão heterogênea no compartimento posterior. Estudo dinâmico axial (B) e mapa colorido (C) demonstrando realce precoce na parte posterior e superficial da lesão com TIC TIPO III (linha vermelha em D). Cinco meses após o tratamento, a ressonância convencional não mostra alteração significativa na intensidade do sinal da lesão (E). Enquanto isso, o estudo dinâmico axial (F) e o mapa colorido (G) mostram uma mudança no padrão do realce, com TIC tipo V (linha vermelha em $\mathrm{H}$ ), indicando boa resposta ao tratamento. A análise histológica mostrou mais de $90 \%$ de necrose tumoral.

permite o diagnóstico precoce de metástases saltadas. Sua sensibilidade está entre 79 e $85 \%$, com especificidade errática. ${ }^{11}$

Quando a lesão suspeita é solitária, assintomática ou localizada em local não propício à biópsia, a cintilografia óssea é indicada para detectar lesões mais acessíveis ao procedimento.

\section{Imagem de Ressonância Magnética de Corpo Inteiro}

A imagem de ressonância magnética de corpo inteiro possui uma excelente resolução espacial e contraste para tecidos moles, sendo desprovido de radiação ionizante. ${ }^{12}$ Essas características, aliadas à alta acurácia no estudo da medula óssea, permitiram maior aplicabilidade na avaliação de MBs, MMs, linfomas e da resposta ao tratamento instituído. A ressonância magnética de corpo inteiro também pode ser útil no monitoramento de sarcomas de tecido mole que metastatizam para os ossos, como lipossarcoma mixóide. ${ }^{9}$

Sua sensibilidade é semelhante à do PET/CT na avaliação medular e caracterização de alterações focais, diferenciando lesões inativas tratadas daquelas em atividade. ${ }^{13}$

Por ser um método muito sensível, a ressonância magnética de corpo inteiro pode induzir à realização desnecessária de exames subcutâneos e biópsias. Os resultados atribuídos ao método estão diretamente relacionados ao uso do protocolo adequado, às sequências corretas e à experiência de quem interpreta os exames. 
Figura 2. Caracterização tecidual de lesões de tecidos moles.

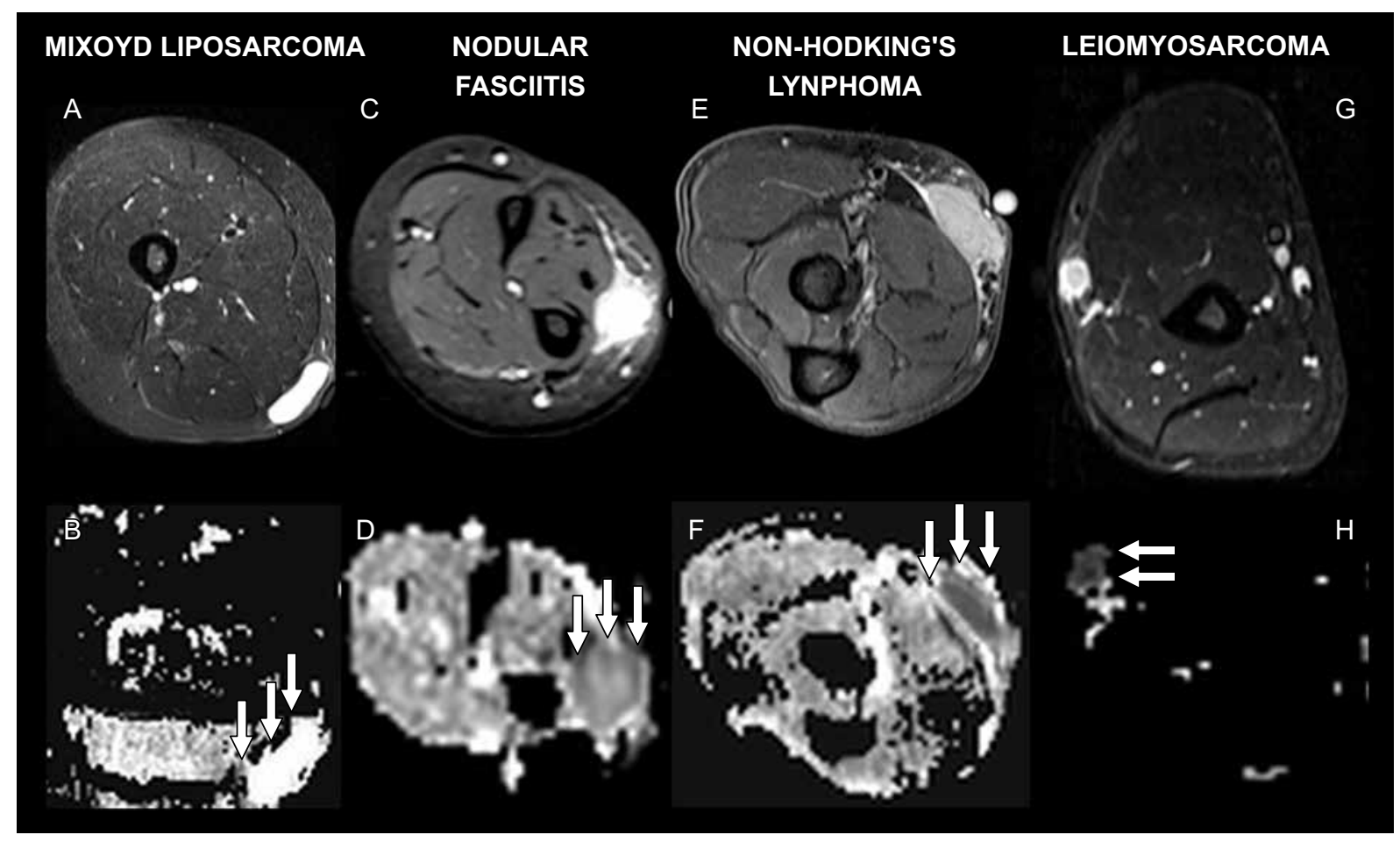

Lipossarcoma mixóide na coxa em T1 com supressão de contraste após administração de gadolínio (A) e mapa $\mathrm{ADC}(\mathrm{B})$ demonstrando $\mathrm{ADC}=2,6 \times 10^{3} \mathrm{~mm}^{2} / \mathrm{s}$.T1-t1 fase nodular do antebraço com supressão de contraste após administração de gadolínio (C) e $\mathrm{ADC}$ ( D) mapa demonstrando $\mathrm{ADC}=1,4 \times 10^{3} \mathrm{~mm}^{2} / \mathrm{s}$. Linfoma não Hodgkin do antebraço em T1-dia-t1 com supressão de contraste após administração de gadolínio (E) e mapa ADC (F) demonstrando $\mathrm{ADC}=0,6 \times 10^{3} \mathrm{~mm}^{2} / \mathrm{s}$. Leiomiossarcoma do braço em $\mathrm{T} 1$ com supressão de contraste após administração de gadolínio (C) e mapa $\mathrm{ADC}(\mathrm{D})$ demonstrando $\mathrm{ADC}=0,97 \times 10^{3} \mathrm{~mm}^{2} / \mathrm{s}$.

Comparado à PET/CT, a RM apresenta maior sensibilidade (68 versus 59\%), especificidade ( 83 versus $75 \%$ ) e valor preditivo positivo ( 88 versus $75 \%$ ), sendo superior na detecção de pequenas lesões e doença difusa. ${ }^{12}$

Tomografia por Emissão de Pósitron - Tomografia Computadorizada (PET/CT)

A PET/CT utiliza radioisótopos submetidos à decomposição de emissões de pósitrons; um anel detector sofisticado identifica fótons coincidentes, registrando a interação por meio de imagens. $\mathrm{O}$ radiofármaco mais utilizado é a fluordesoxiglicose marcada com Fluor-18 (FDG-F18), que é análoga à glicose. Tumores mais anaplásicos geralmente apresentam taxas aumentadas de glicólise e captação de FDG-F18 em comparação com neoplasias benignas ou malignas de baixo grau - há uma forte correlação entre captação de FDG-F18 e grau histológico, com implicações prognósticas. $^{4}$

O método é mais sensível na detecção de lesões líticas do que blásticas. A sensibilidade é de $91 \%,{ }^{11}$ com variabilidade significativa: $100 \%$ em osteossarcoma, $85,7 \%$ em recidivas e $95 \%$ em MBs. ${ }^{13}$ O Fluor-18-PET é 95\% sensível e 75\% específico no diagnóstico de sarcomas de tecidos moles. ${ }^{4}$ No entanto, alguns tumores benignos (lesões histiocíticas ou ricas em células gigantes) podem apresentar maior acúmulo de FDG. ${ }^{4}$

A PET/CT pode ser utilizada no estadiamento, reestadiamento e monitoramento da resposta terapêutica. ${ }^{13}$ Também permite distinguir doença residual de lesões cicatriciais, impactando no manejo clínico. 
Tabela 2. Vantagens e desvantagens dos métodos de imagem usados na avaliação sistêmica de sarcomas musculoesqueléticos.

\begin{tabular}{|c|c|c|}
\hline Método & Advantages & Disadvantages \\
\hline $\begin{array}{l}\text { TC (tórax, } \\
\text { abdômen } \\
\text { e pelve) }\end{array}$ & $\begin{array}{l}\text { - Acessível; } \\
\text { - TC de tórax: aumento da sensibilidade na detecção de } \\
\text { metástase pulmonar; } \\
\text { TC de abdome e pelve: estadiamento de sarcoma sinovial, } \\
\text { epitelióide, células claras, leiomiossarcoma, angiossarcoma } \\
\text { e lipossarcoma mixóide. }\end{array}$ & - Radiação ionizante $(*)$ \\
\hline BSC & $\begin{array}{l}\text { - Acessível; } \\
\text { - Avaliação de todo o sistema esquelético em um único exame; } \\
\text { - Sensível; detecta mudanças fisiológicas antes de mudanças } \\
\text { - Pilar no diagnóstico e avaliação da metástase óssea; } \\
\text { - Acompanhamento de lesões com alta taxa de recorrência } \\
\text { ou potencial metastático; } \\
\text { - Diagnóstico precoce de metástases saltadas. }\end{array}$ & $\begin{array}{l}\text { - Radiação ionizante } \rightarrow \text { a } \\
\text { - Lesões não envolvidas por reações } \\
\text { reativas ou muito anaplásicas; } \\
\text { - O tecido ósseo pode não capturar (por } \\
\text { exemplo, mieloma múltiplo, tireoide ou } \\
\text { metástase de CA renal); } \\
\text { - Inadequado na avaliação da resposta } \\
\text { terapêutica - fenômeno flare; } \\
\text { - Não muito específico. }\end{array}$ \\
\hline WBMRI & $\begin{array}{l}\text { - Diferenciação entre resposta terapêutica e avanço da doença; } \\
\text { - Resolução superior de contraste em partes moles, boa } \\
\text { - } \text { resolução espacial; } \\
\text { - Squisição de imagens mais rápida que PET/CT; } \\
\text { - Diagnóstição ionizante ou necessidade de usar contraste; } \\
\text { - Previsão de risco iminente de fratura; } \\
\text { - Alta precisão no estudo da medula óssea. }\end{array}$ & $\begin{array}{l}\text { - Custo; } \\
\text { - Acessibilidade; } \\
\text { - Tempo para aquisição da imagem pode } \\
\text { requerer sedação; } \\
\text { - Contra-indicações da ressonância } \\
\text { magnética. }\end{array}$ \\
\hline $\mathrm{PET} / \mathrm{CT}$ & $\begin{array}{l}\text { - Diagnóstico precoce; } \\
\text { - Estadiamento mais preciso das metástases ósseas do que a } \\
\text { cintilografia; } \\
\text { - Avalia a viabilidade do tumor/tecido, acesso à atividade } \\
\text { metabólica; } \\
\text { - Distingue doença residual de lesões cicatriciais; } \\
\text { - Facilita a avaliação da resposta terapêutica; } \\
\text { - Detecta pequenos nódulos pulmonares; } \\
\text { - Permite orientar biópsias para áreas metabolicamente ativas } \\
\text { do tumor; } \\
\text { - Exames realizados em } 30 \text { minutos. }\end{array}$ & $\begin{array}{l}\text { - Alto custo; } \\
\text { - Pouco acessível; } \\
\text { - Radiação ionizante } \\
\text { - Contraste limitado em partes moles; } \\
\text { - Sobreposição na atividade metabólica } \\
\text { de lesões benignas e malignas; } \\
\text { - Infecções e processos granulomatosos } \\
\text { têm alto consumo de glicose; } \\
\text { - O tempo de aquisição da TC impossibilita } \\
\text { o tempo extra para aquisição do PET. }\end{array}$ \\
\hline PET/MRI & $\begin{array}{l}\text { - Diagnóstico precoce; } \\
\text { - Estadiamento mais preciso das metástases ósseas do que a } \\
\text { cintilografia; } \\
\text { - Avalia a viabilidade do tumor/tecido, acesso à atividade } \\
\text { metabólica; } \\
\text { - Permite distinguir doença residual de lesões cicatriciais; } \\
\text { - Facilita a avaliação da resposta terapêutica; } \\
\text { - Permite orientar biópsias para áreas metabolicamente ativas } \\
\text { do tumor; } \\
\text { - Melhor localização anatômica das lesões; } \\
\text { - Superior que PET/CT no SNC, fígado e medula espinhal. }\end{array}$ & $\begin{array}{l}\text { - Alto custo; } \\
\text { - Muito pouco acessível; } \\
\text { - Radiação ionizante } \rightarrow \text { ac } \\
\text { - Protocolos, indicações e acurácia } \\
\text { quantitativa ainda em avaliação; } \\
\text { - O tempo de aquisição da imagem pode } \\
\text { exceder } 1 \text { hora; } \\
\text { - Avaliação limitada do parênquima } \\
\text { pulmonar. }\end{array}$ \\
\hline
\end{tabular}

a (-) Dose efetiva estimada para adultos 1-10 mSv; dose efetiva estimada para crianças 0,3-3 mSv.

b (-) Dose efetiva estimada para adultos 10-30 mSv; dose eficaz estimada para crianças 3-10 mSv.

Fonte: Jordan and colleagues..$^{14}$ 
Tomografia de Emissão de Pósitrons - Imagem de Ressonância Magnética (TEP/IRM)

TEP/IRM associa TEP com IRM, usualmente utilizando FDG-F18.

É restrito, por custo e disponibilidade. No componente TEP, apresenta as características já descritas, associadas aos achados da RM, com reduzida exposição à radiação. ${ }^{15}$ Permite melhor avaliação local e sistêmica do que outros métodos, sendo superior ao PET/CT na avaliação do sistema nervoso central, fígado e medula espinhal, mas é limitado no estudo do parênquima pulmonar. ${ }^{16}$

A PET/RM parece muito promissora, agregando informações sobre o perfil metabólico (PET) à excelente resolução (RM). Mais estudos de custo-efetividade e mudanças nos resultados são necessários para defini-lo na investigação de rotina de sarcomas musculoesqueléticos. ${ }^{16}$

\section{Considerações Finais}

O conhecimento das indicações dos métodos de imagem disponíveis para avaliação de SMSs é fundamental para evitar-se a prescrição desnecessária de exames e definir o planejamento terapêutico mais adequado para cada situação clínica apresentada.

\section{Referências}

1. Caracciolo JT, Letson GD. Radiologic approach to bone and soft tissue sarcomas. Surg Clin North Am. 2016;96(05):963-976.

2. Guedes A, Oliveira MBR, Costa FM, Melo AS. Updating on bone and soft tissue sarcomas staging. Rev Bras Ortop (Sao Paulo). 2021;56(4):411-418.

3. Pennington Z, Ahmed AK, Cottrill E, Westbroek EM, Goodwin ML, Sciubba DM. Systematic review on the utility of magnetic resonance imaging for operative management and follow-up for primary sarcomalessons from extremity sarcomas. Ann Transl Med. 2019;7(10):225.
4. Kransdorf MJ, Bridges MD. Current developments and recente advances in musculoskeletal tumor imaging. Semin Musculoskelet Radiol. 2013;17(02):145-155.

5. Miller BJ, Avedian RS, Rajani R, et al Musculoskeletal Oncology Research Initiative. What is the use of imaging before referral to an orthopaedic oncologist? A prospective, multicenter investigation. Clin Orthop Relat Res. 2015;473(03):868-874.

6. Nystrom LM, Reimer NB, Dean CW, et al. Evaluation of imaging utilization prior to referral of musculoskeletal tumors: a prospective study. J Bone Joint Surg Am. 2015;97(01):10-15.

7. Costa FM, Martins PH, Canella C, Lopes FPPL. Multiparametric MR imaging of soft tissue tumors and pseudotumors. Magn Reson Imaging Clin N Am. 2018;26(04):543-558.

8. Mavrogenis AF, Angelini A, Vottis C, et al. State-ofthe-art approach for bone sarcomas. Eur J Orthop Surg Traumatol. 2015;25(01):5-15.

9. Patel DB, Matcuk GR Jr. Imaging of soft tissue sarcomas. Linchuang Zhongliuxue Zazhi. 2018;7(04):35.

10. Oliveira MB, Mello FC, Paschoal ME. The relationship between lung cancer histology and the clinicopathological characteristics of bone metastases. Lung Cancer. 2016;96(01):19-24.

11. Shen G, Deng H, Hu S, Jia Z. Comparison of choline-PET/ CT, MRI, SPECT, and bone scintigraphy in the diagnosis of bone metástases in patients with prostate cancer: A meta-analysis. Skeletal Radiol. 2014;43(11):1503-1513.

12. Morone M, Bali MA, Tunariu N, et al. Whole-Body MRI: Current applications in oncology. AJR Am J Roentgenol. 2017;209(06):W336-W349.

13. Behzadi AH, Raza SI, Carrino JA, et al. Applications of PET/CT and PET/MR Imaging in primary bone malignancies. PET Clin. 2018;13(04):623-634.

14. Jordan DW, Becker M, Brady S, Feng JC, Jafari ME, Johnson LM et al. American College of Radiology ACR. Appropriateness Criteria ${ }^{\circledR}$. Radiation Dose Assessment Introduction (revised 2020). Reston, VA: American College of Radiology. https://www. acr.org/-/media/ACR/Files/Appropriateness-Criteria/ RadiationDoseAssessmentIntro.pdf).

15. Ehman EC, Johnson GB, Villanueva-Meyer JE, et al. PET/MRI: Where might it replace PET/CT? J Magn Reson Imaging. 2017;46(05):1247-1262.

16. Martin O, Schaarschmidt BM, Kirchner J, et al. PET/MRI versus $\mathrm{PET} / \mathrm{CT}$ for whole-body staging: Results from a single-center observational study on 1,003 sequential examinations. J Nucl Med. 2020;61(08):1131-1136. 